\title{
Life by design: Philosophical perspectives on synthetic biology
}

\author{
Bernadette Bensaude Vincent ${ }^{\mathrm{a}}$ \\ Université Paris 1-Panthéon-Sorbonne, France
}

\begin{abstract}
Biology is Technology", this title of a book authored by bioengineer Rob Carlson captures the essence of synthetic biology. This novel research field is in the hands of engineers, who are in charge of redesigning life or designing new forms of life for specific purposes. In the aftermath of "the century of the gene" (Evelyn Fox Keller, Cambridge Mass, Harvard University Press, 2002) he comes the century of "life by design". As the emergence of molecular biology allowed reading the code of life, it seems quite natural to rewrite it with the alphabet. "From reading to writing the genetic code", this is how Craig Venter, a genetic engineer who designed the first bacteria with a synthetic genome in 2010, explains and legitimizes his research programme. It seems to be a logical inference based on a chronological sequence.

The prospect of designing organisms triggers the promise of manufacture of all sorts of organisms to meet societal demands or human desires and fantasies: From bacteria-workers to the creation of new forms of life or even...immortal life. Just as in nanotechnology, synthetic biology develops an "economy of promises". However synthetic biology seems to go one step further. While nanotechnology has been advertised with the slogan "shaping the world atom by atom" in the 2000 US National NanoInitiative, synthetic biology opens up the more challenging perspective of designing organisms that will remake the world for us. Re-engineered yeasts or bacteria will serve as pharmaceutical plants producing drugs. Synthetic algae will provide renewable fuel for our daily consumption of energy. Synthetic bacteria will decontaminate the soils polluted by chemicals and nuclear waste.

This paper outlines a number of distinctive features of this emerging field in the constellation of bionanotechnologies. It then insists on the variety of research agendas and strategies gathered under the umbrella "synthetic biology". While redesigning life is the central goal, synthetic biologists do not develop a uniform view of living organisms.
\end{abstract}

\section{A booming discipline short of discipline ${ }^{1}$}

Synthetic biology is a booming discipline, which has attracted a lot of policy makers' attention, public and private investments over the past decade as well as young talents Although synthetic biology becomes part of the curriculum in a number of universities, it is not strictly speaking a sub-discipline of biology for two major reasons: i) it challenges the divide between pure and applied research, between

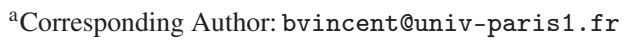

This is an Open Access article distributed under the terms of the Creative Commons Attribution License 4.0, which permits unrestricted use, distribution, and reproduction in any medium, provided the original work is properly cited. 
science and technology, as well as between academia and laypeople and ii) it blurs the clear-cut distinctions between disciplines based on epistemic criteria.

First, synthetic biology is not just an academic discipline. Although it nested in the niche of prestigious universities such as MIT, Stanford, ETH Zurich, from the very beginning its champions have worked hard to promote a new model of academic sociability and responsibility. The annual students competition iGEM (International Genetically Modified Machine) and the movement of garage biology appear as serious efforts to open academic knowledge.

The iGEM competition subverts the hierarchical organization of laboratory life with seniors and doctors supervising juniors and undergraduates. It appeals to the creativity of young people by encouraging their self-organization and autonomy and applying non-standard criteria of evaluation of research projects. They subsequently return the products of their designs to the registry. Drew Endy and Rob Carlson are convinced that synthetic biology, as they shape it, is so easy that it is accessible to laypeople. Accordingly they are actively promoting garage biology with the view to develop a critical mass of data for synthetic biology to take off. They also promote new property regimes aimed at establishing various forms of "open biology" inspired by the open source movement in information technology. The Biobricks Foundation develops a Registry of Standardized Biological Parts at MIT, which is gradually increased by the iGEM students.

"The Registry is based on the principle of "get some, give some". Registry users benefit from using the parts and information available from the Registry in designing their engineered biological systems. In exchange, the expectation is that Registry users will, in turn, contribute back information and data on existing parts and new parts that they make to grow and improve this community resource" [3].

The regime of openness subverts the current practice of patenting every step and challenges the divide between amateurs and experts. Its ultimate ambition is to generate a new social order through innovative technoscientific practices. [4]

Second, synthetic biology combines knowledge from a large number of disciplines, including molecular biology, engineering, mathematics, chemistry, and physics. There is a variety of research agendas gathered under the umbrella "synthetic biology" Biobricks, synthetic DNA, xeno-DNA, minimal genomes, and protocells could arguably be presented as exemplars of the current movement of Converging Technologies prompted by the nanotechnology wave. Yet they belong to a special branch of biology often coupled with systems biology. Systems biology, the sister science, aims at understanding collective behaviour of biological interactions through computing and modelling, while synthetic biology is about synthesizing biological entities.

\section{A variety of research agendas}

The official label "Synthetic Biology" was adopted on the occasion of the Synthetic Biology 1.0 Conference organized in June 2004, at MIT by Drew Endy and Tom Knight, both members of the department of Biology and Biological Engineering of this Institute. The name of the discipline has been modelled after the phrase "synthetic chemistry" [5], and a number of synthetic biologists rely on the analogy with the history of chemistry to legitimize their research programmes [6] Synthetic biologists developed a comparison between the transition from analytical chemistry to synthetic chemistry in the $19^{\text {th }}$ century and the recent shift from molecular biology to synthetic biology. As a result, the development of synthetic biology appears as the ineluctable consequence of the analytical phase identified with genetics and genomics [7]. Since synthetic chemistry generated the flourishing chemical industries that synthetic biology claims to overthrow and replace in the near future by more environmentally friendly biotechnology, it seems to be a good tactic. More generally synthetic biologists retain from chemists their characteristic method of "knowing through making". Some of them explicitly promote a kind of "reverse analysis", although modelling and simulating are used beforehand. 


\section{ORIGINS}

"By taking apart an old clock, you could probably come up with a pretty good guess at how it works. But a more concrete understanding of the clock mechanism might be obtained by designing and building one's own clock out of similar parts. Contemporary biology presents us with similar reverseengineering problems" [8].

However the modular approach developed by Drew Endy takes inspiration from an alternative disciplinary model, promoted in electronic and software engineering. The Biobrick program first developed at MIT then in the consortium SynBERC is driven by the ambition of applying the principles of professional engineering to living organisms. Drew Endy claims to make routine the engineering of synthetic biological systems that behave as expected. [9] His program rests on the creation of a database, a collection of well-characterized biological parts that can be assembled in devices and systems. His engineering approach rests on a few basic rules: standardization, modularization, interoperability, transparency and reliability. In a sense their synthetic biology is a continuation of the "engineering ideal in American culture" [10].

Research programs aimed at making minimal genomes share the project of implementing desired functionalities in a chassis. However they differ from the Biobrick program as the emphasis is less on intentional design and more about demonstrating capabilities of challenging nature. Proofs of concept are celebrated as records in sports competitions.

The branch of synthetic biology often referred to as "xeno-biology" or "unnatural-biology" aims at synthesizing new types of nucleic acids with a view to generating novel forms of life that evolution could have made. It is part of a broader program of "universal biology", whose objective is to move beyond the circumstances of the particular origins of life on earth and to identify the general principles of life according to the universal laws of physics and chemistry. It is driven by an ambitious cognitive goal to better understand the past, the origin of life as well as the principles that will shape life in the future. However this cognitive goal is intertwined with more practical expectations to design bio-devices and machines for more immediate technological or medical applications.

Design seems to be the major link that ties together the constellation of multidisciplinary groups usually gathered under the umbrella synthetic biology, since they have quite diverse research agendas. To the question "What's in a name" [syntheticbiology] the editor of an issue of Nature Biotechnology [11] did not get a uniform answer in 2009, although a consensus emerged from a dozen of answers around two key notions: engineering and design. This consensus nevertheless hardly dissimulates the diversity of research aims and methods. For Endy and his group we need more standardization and quantitative datasheets. Refinement and standardization of synthetic biological parts and devices [12]. Steve Benner, by contrast, argues that engineering "requires tools originally designed by nature's greatest tinkerer: evolution" [13]. He recommends, more synthesis to test the hypotheses generated by computation, in silico. Only through in vitro synthesis engineers learn what it takes to get something to work [14]. A number of synthetic biologists insist on the contrary, that we need more coupling of systems and synthetic biology [15]. In particular, some of them claim that the right scale is not parts but systems" [16]. Clearly the booming discipline of synthetic biology has not developed a dominant paradigm and it is not going to settle down on a unique research agenda in the next few years.

\section{What is synthetic life?}

Although synthetic biology is promoted as an engineering science, essentially oriented toward applications and open to societal and environmental demands, it relies on theoretical assumptions concerning the nature of living organisms and their relations to their environment. The underlying metaphysical assumptions of synthetic biologists occasionally surface in their public discourses or publications. As many scientists they are fond of metaphors and we know that far from being neutral didactic devices, metaphors are extremely performative. 
Undoubtedly, all scientists working in the field of synthetic biology share a common credo that life is information. They are concerned with the molecular nature and structure of life components only in as much as they are operational units. When they re-engineer existing microorganisms they consider them as functional units - devices or machines - performing specific tasks. Nature is viewed as a source of programs as much as a source of raw materials.

Therefore the computer metaphor is the most abundant in public presentations of synthetic biology. For instance in 2010, Craig Venter presented his synthetic bacteria significantly named Mycoplasma laboratorium: "this is the first self-replicating cell we h've had on the planet whose parent is a computer" [17]. In this case the computer stands only for the software. As science writer Philipp Ball commented on Venter's earlier result in 2007: "If your computer doesn't do the things you want, give it a new operating system" [18]. The painstaking laboratory work and technical skills needed to insert a new genome in a cell are simply overlooked. In a similar vein, George Church from Harvard Medical School, uses the computer metaphor to portray living organisms as universal machines:

\begin{abstract}
"Just as computers were universal machines in the sense that given the appropriate programming they could simulate the activities of any other machine, so biological organisms approached the condition of being universal constructors in the sense that with appropriate changes to their genetic programming, they could be made to produce practically any imaginable artefact. A living organism, after all, was a ready-made, prefabricated production system that, like a computer, was governed by a program, its genome" [19].
\end{abstract}

In the Biobricks program the emphasis is more on the hardware. Endy's modular approach of bioengineering - moving step-by-step from independent parts, to devices and then to system - is clearly inspired by electronic circuitry. In the biobricks approach, synthesizing is like playing with Lego bricks. For Rob Carlson: "Building with Legos is an excellent metaphor for future building with biology. The utility and unifying feature of Legos, Tinkertoys, Erector Sets, Zoob, or Tente is that the pieces fit together in very understandable and defined ways' [1, p.9] All synthetic biologists using the computer metaphor describe life in terms of familiar, man-made machines and their purpose is to promote to construct rational and reliable artefacts that get rid of all the messiness and unpredictability of natural systems. In this case the ambition of synthetic biologists is to implement the principles of rational design into natural systems. Their strategy could be labelled "technomimetism" since it often dismisses biomimetism as a poor amateurish strategy:

\begin{abstract}
"If biological engineering were aviation, it would be at the birdman stage: some observation and some understanding, but largely naive mimicry. For the field to really take flight, it needs the machinery of synthetic biology. [...] At the turn of the last century, the Wright brothers achieved manned flight not by mimicking natural systems, but by applying the principles of engineering and aerodynamics. Similarly, synthetic biology allows us to dispense with biological mimicry and design life forms uniquely tailored to our needs. In doing so, it will offer not only fundamental insights into questions of life and vitality but also the type of exquisite precision and efficiency in creating complex traits that genetic engineers could previously only dream of" [20].
\end{abstract}

A group of synthetic biologists who develop a chemical approach to synthetic biology seem more concerned with disentangling the complexity of natural systems through making tentative artificial analogues such as miminal cells or synthetic nucleic acids. They want to understand the basic principles of natural systems such as cells, "why this and not that" works, as P. Luigi Luisi put it [21]. Their basic assumption is that life is more than a program written in DNA; it is a process involving the dynamic interaction of thousands of molecular components. Among many projects, they synthesize never-born proteins and test them against actual proteins in order to see whether the latter have something particular, since they are the outcome of a contingent evolution rather than of rational design. 


\title{
ORIGINS
}

In this case the emphasis is on the gap between the artificial and the natural. When a chemist such as Steve Benner boasted to "fix God's mistakes" by redesigning DNA, he mainly sought to outline the role of contingency and circumstances which have shaped the actual structure of natural DNA.

\begin{abstract}
"The structure of DNA is far from perfect because it reflects events that occurred at the origin of life and in subsequent episodes of life where constraints on the structure of biomolecules were quite different from those today, and certainly not conducive to creating a biomolecule that serves the goals of the analytic chemists, the bioengineer, or the synthetic biologists. Fortunately the theory and synthesis are both adequate to make a better genetic material" [22].
\end{abstract}

A more perfect DNA respectful of the laws of electrochemistry would not work. Indeed a number of synthetic biologists argue that artificial genetic codes may be needed in case of a catastrophic event that would erase life as it is from the earth [23].

Quite often, synthetic biologists realize the complexity of natural systems through failed attempts at mimicking or overtaking nature. Learning from failure is typically the attitude developed by one of the pioneers of synthetic biology. Michael Elowitz from Caltech who published a landmark paper on a synthetic oscillatory network of transcriptional regulators [24]. But the oscillator couldn't work because it only took into account transcriptional factors. Elowitz and his collaborators consequently considered intrinsic and extrinsic noise as an essential ingredients of genetic circuits [25]. Stochasticity and nonlinearity make the output partly unpredictable. Far from trying to get rid of noise synthetic biology should take it into account for constructing new circuits, to turn the obstacle into a parameter of design. As Richard Jones argued against Eric K. Drexler's visions of "engines of creation" modelled after Lego blocks, it is vital to take into account the specific features of "soft machines" like biological systems [26]. They do not operate along the same standards and mechanisms as the products of rational design.

Paying attention to the unique features of biological systems and using epigenetic features such as cell interactions, signalling pathways as leverages is also the lesson outlined by Priscilla Purnick and Ron Weiss for "the second wave biology":

"As we move in the second wave of synthetic biology, it is important to incorporate classical
engineering practices, such as modularity, component testing, standards, interfaces, libraries of parts
and computer-aided design. However we cannot ignore the unique features of biological systems that
might hamper the straightforward use of the well-meaning and well-organized practices" [16, p. 420].

To conclude, after ten or fifteen years of intensive development and institutionalization, synthetic biology is no longer an emerging discipline. It is still an extremely attractive and booming research field with a strong research agenda centred around the project of "life by design". However it retains the epistemic diversity that characterized its early days and no mainstream seems to take over and become the dominant paradigm.

\section{References}

[1] R. Carlson, Biology is Technology. The promise, peril and new business of engineering life, (Harvard University Press, Cambridge Mass., 2010)

[2] E. Fox Keller, The Century of the Gene (Harvard University Press, Cambridge Mass., 2002)

[3] Registry of Standardized Biological Parts http://partsregistry .org/MainPage

[4] S. Hilgartner, BioSocieties 7, 188-207 (2012)

[5] L. Campos, "That was the synthetic biology that was", in M. Schmidt et al. (eds.), Synthetic Biology, p. 6-20 (Springer, 2009)

[6] B. Bensaude-Vincent, "Discipline Building in Synthetic Biology", Studies in History and Philosophy of Biological and Biomedical Sciences, "Philosophical Perspectives on Synthetic Biology" 44 (2), 122-129 (2013) 
[7] B.J. Yeh, A. Lim Wendell, Nature Chemical Biology, 3, 521-525 (2007)

[8] D. Sprinzac, M. Elowitz, Nature, 348, 443-445 (24 Nov. 2005)

[9] D. Endy, Nature, 428, 449-453 (24 November 2005)

[10] P. Rabinow "Symposium on Paul Rabinow. An Account of his work at SYNBERC", http: //www .ucpress journals . com/reprintinfo.asp.DOI : 10.1525/lal .2009.21.3.301

[11] “What's in a name?"Nature Biotechnology, 22 (12), 1071-1073 (Dec. 2009)

[12] B. Canton, A. Labno, D. Endy, Nature Biotechnology, 26 (7), 787-793 (2008)

[13] S.A. Benner, "Synthesis as a route to knowledge", Biological Theory, 8, 357-367 (2013)

[14] M. Sismour, S. Benner, Expert Opinion on Biological Therapy, 5 (11) 1410-1414 (2005)

[15] P. Schwille, Science, 333, 1252-1254 (2011)

[16] P. Purnick, R. Weiss, Nature Reviews Molecular Cell Biology, 10, 410-23 (June 2009)

[17] USA Today $(5 / 20 / 2010)$

[18] P. Ball, Nature, 448, 32, 191(5 July 2007)

[19] G.M. Church, E. Regis, Regenesis, How Synthetic Biology will reinvent Nature and Ourselves, p.4 (Basic Books, New York, 2012)

[20] Editorial, Nature Biotechnology, 27, 12, 1059 (2009)

[21] P.P. Luisi, C. Charabelli (eds) Chemical Synthetic Biology (John Wiley \& Sons, 2011)

[22] S.A. Benner, "Redesign DNA: Fixing God's mistakes" The Pittcon Program 201 Conference, Capstone, March 14, 2012, http://www .pittcon.org/technical/capstone.php.

[23] P. Marlière, "Prométhée, Pandore et Petri", 24 mai 2010, http://www.boursorama.com/ forum-global-bioenergies-promethee-pandore-et-petri-424709356-1

[24] M. Elowitz, S. Leibler, Nature, 403, 20, 335-338 (2000)

[25] Sprinzack \& Elowitz, Nature Reviews, 438, 24 November 2005, 443-448 (2005)

[26] R. Jones, Soft Machines (Oxford University Press, Oxford, New York, 2004)

\footnotetext{
1 This title has been used by Geof Bowker and Bruno Latour to present the social studies of science in France in the 1980s (Social
} Studies of Science, 17: 4, 715-748 (1987). 